PERIODICALS OF ENGINEERING AND NATURAL SCIENCES

Vol. 5 No. 1 (2017) - Special Issue (Recent Topics in Environmental Science)

Available online at: http://pen.ius.edu.ba

\title{
Pyrolysis Kinetics of Pine Sawdust in a Fixed Bed
}

\author{
Melek Yilgin \\ Department of Chemical \\ Engineering, Faculty of \\ Engineering, Firat University, \\ 23119, Elazı̆ , Turkey
}

\author{
Dursun Pehlivan, \\ Department of Chemical \\ Engineering, Faculty of \\ Engineering, Frrat University, \\ 23119, Elazı̆g, Turkey
}

\author{
Ercan Aydoğmuş \\ Department of Chemical \\ Engineering, Faculty of \\ Engineering, Frrat University, \\ 23119, Elazı̆g, Turkey
}

\author{
Neslihan Duranay \\ Department of Chemical \\ Engineering, Faculty of \\ Engineering, Frrat University, \\ 23119, Elažğ, Turkey
}

\begin{abstract}
Currently worldwide studies are being done on the utilisation of lignocellulosic materials or biomasses as substitutes of fossil fuels to afford energy needs of today's world. Pyrolysis is one of the most promising techniques for apprising biomass into economically viable renewable fuels. In this work, pyrolysis behaviour of pine sawdust was investigated experimentally in a fixed bed system with mass measurements under nitrogen as sweeping gas.

The main objective was to interpret mass loss of pine sawdust during pyrolysis at varied heating rates and to estimate kinetic constants using the best mathematical model among the popular solid phase decomposition models. Regression tests are separately applied to conversion data for $473-593 \mathrm{~K}$ and $593-773 \mathrm{~K}$ temperature ranges, corresponding respectively decomposition of hemicelluloses and cellulose, and cellulose and lignin. The quality of fit increased with heating rate and none of the proposed models had any superiority to others. The results implied that volatiles evolution during pyrolysis was increasingly controlled chemically with heating rate.
\end{abstract}

Keywords: Pine wood, pyrolysis, kinetics, fixed bed

\section{Introduction}

Depletion in the fossil fuel reserves, considerations about global warming and environmental pollution caused by fossil fuel usage has persuaded the efforts to seek renewable energy options worldwide. Biomass can be looked upon environmentally-friendly and sustainable energy source to reduce net carbon emissions $[1,2]$. Some benefits on the environment can be acquired from the ease of use of agricultural and forest residues and the raw materials involving them. If the bio-wastes are not handled properly, they may create major environmental problems [3].

Thermochemical conversion processes such as combustion, gasification and pyrolysis of lignocellulosic biomasses have received very much attention as methods for renewable energy and fuel production during the last decades [4]. These technologies, which come usually into mind in environmental issues, furnish perfect ways in the utilisation of agricultural and forest wastes for supplying energy. Lignocellulosic biomasses are usually heterogeneous materials of complex chemical structure. Because their physical and chemical compositions vary over a wide range depending on the source, the applicability of thermo-chemical process technologies has become more complicated. For example, wood is composed of hemicelluloses, cellulose and lignin which decompose respectively 225$325^{\circ} \mathrm{C}, 305-375{ }^{\circ} \mathrm{C}$ and $250-500{ }^{\circ} \mathrm{C}$ temperature ranges [5].

Among the processes, pyrolysis has received major consideration because it is not only a one-step process but also first stage of combustion or gasification processes. During pyrolysis, the macromolecules of biomass are decomposed to form a bio char while concurrently evolving condensable vapours (liquids) and gas of lighter molecular mass than the parent molecules. The liquids and gases obtained can be used as fuels where their composition and heating value are appropriate [6]. Thermal decomposition kinetics of biomass is of prime importance in conversions for energy and secondary renewable products to design effectively any thermo-chemical process [7].

Thermal decomposition reactions during pyrolysis of wood can be tracked by measuring continuously its mass loss as in a traditional Thermal Gravimetric Analysis (TGA) and quantitative methods developed for reaction chemistry can be applied to obtain kinetic parameters of reaction order, activation energy and preexponential factor [8]. These parameters are functions of heating rate, material size, moisture content and heating medium. Thermal analysis results are 
dominantly used factors to form the reactivity equations. Although the magnitude of pre-exponential factor depends on the nature of decomposing material, activation energy is affected considerably by heating rate. For this reason, reactivity of wood is usually expressed by its own activation energy [9]. With the growing concern given on biomass pyrolysis for conversions into renewable fuels, immense literature on the wood decomposition kinetics has accumulated during the past decades. Although TGA instruments are sophisticated devices for decomposition kinetics of samples as few amounts of solid powder, which may in some instances not be representative of whole material, valuable results could be obtained with larger amounts than those used in TGA. It is therefore, the objective of this work to track the mass of decomposing biomass during pyrolysis and use the data to elucidate the suitability of the mathematical models given in literature until now.

\section{Material and Methods}

Pine wood chips for this study were supplied from a local wood workshop in Elazig. After grinding, they were sieved and $16+35$ mesh size is retained for the experiments. Mass data during pyrolysis of sample was obtained using the system shown in Figure 1. The heating chamber consists of an electrically heated $35 \mathrm{mmIDx} 90 \mathrm{mmOD} 120 \mathrm{~mm}$ length vertical chamber of refractory block holding heating elements. A $20 \mathrm{mmIDx} 22 \mathrm{mmOD} 250 \mathrm{~mm}$ length quartz tube was situated into the chamber. At the inlet, the tube has a circular refractory lid with $10 \mathrm{~mm}$ diameter hole which held a bended glass tube for entrance of nitrogen as sweeping gas. Quartz tube has a $14 \mathrm{~mm}$ diameter stainless steel wire mesh basket inside, fitted to top end of a $1.4 \mathrm{~mm}$ diameter and $250 \mathrm{~mm}$ length vertical stainless steel rod. The bottom end of the rod is fitted to a square stainless steel plate standing on a top balance of $0.001 \mathrm{~g}$ accuracy. To prevent condensation of the pyrolysis vapours on the balance, bottom end of the quartz tube has a glass adapter whose diameter decrease smoothly to $6 \mathrm{~mm}$ towards the rod.

Before the experiments, refractory lid of quartz tube was removed and $1.00 \mathrm{~g}$ pine wood sample was dropped on the basket using a glass funnel. After reassembling the lid, nitrogen flow $\left(100 \mathrm{ml} \cdot \mathrm{min}^{-1}\right.$.) was allowed to pass through the quartz tube for $5 \mathrm{~min}$. After that, heating of the chamber was started and first mass reading was taken. The mass recordings during pyrolysis were made at 2 min. intervals. Heating and temperature control of the chamber were accomplished by using a variable output voltage transformer which powers a PID programmable temperature controller with a NiCr thermocouple positioned at the same level with the basket in the quartz tube. Nitrogen flow was maintained throughout the run. Heating rates of 5, 10 and $15^{\circ} \mathrm{C} / \mathrm{min}$. were applied in the separate runs.

Pyrolysis was continued $15 \mathrm{~min}$. after heating the chamber to the final $500{ }^{\circ} \mathrm{C}$ temperature. After that heating was stopped and the system was left to cool under nitrogen flow. The basket was removed and mass of pyrolysis residue on the basket was weighted to compare to the last mass readings.

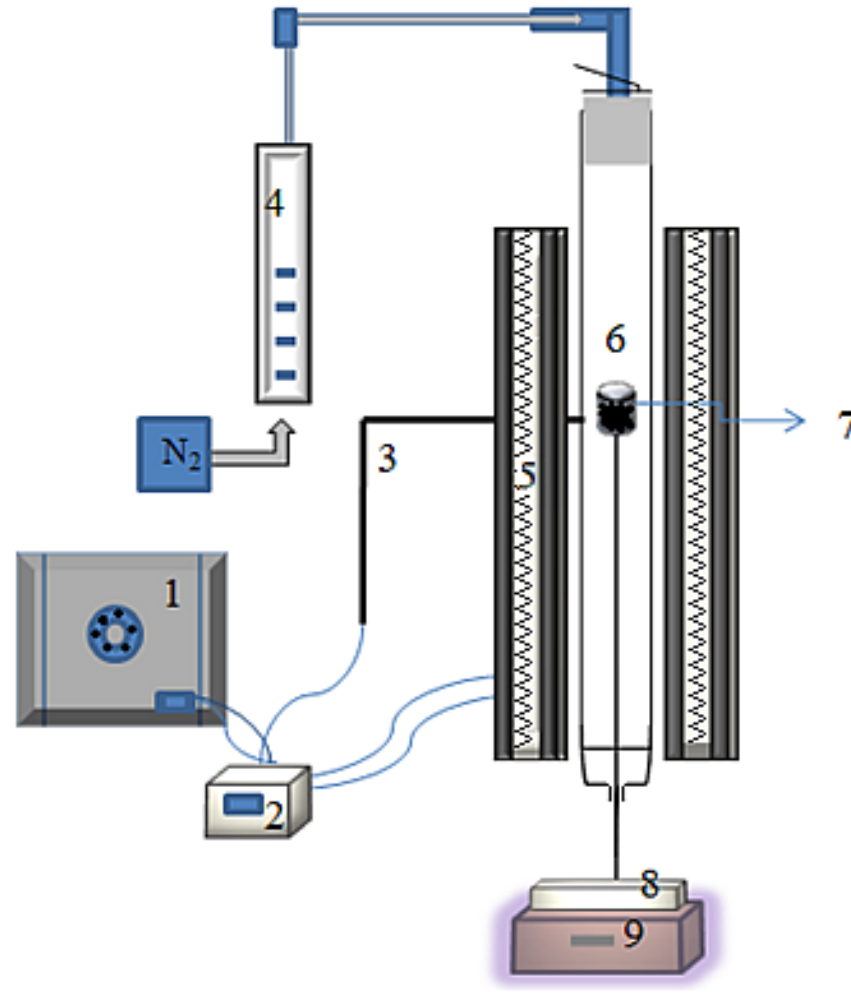

Figure 1. Experimental system; 1, variable output transformer; 2, temperature controller; 3, thermocouple; 4, flow meter; 5, vertical furnace; 6, quartz tube; 7, basket; 8, supporting plate; 9, top balance

\section{Mathematical Model}

Pyrolysis rate of a solid depends on the temperature and the amount of material. If it is assumed that only a single reaction is involved, the following equations for $\alpha$ conversion ratio and its changing rate can be used to describe the progress of reaction:

$\alpha=\frac{\mathrm{W}_{0}-\mathrm{W}}{\mathrm{W}_{0}-\mathrm{W}_{\infty}}$

$\frac{\mathrm{d} \alpha}{\mathrm{dt}}=\mathrm{k}(\mathrm{T}) \mathrm{f}(\alpha)$

where $\mathrm{t}$ and $\mathrm{T}$ are time and absolute temperature respectively. Subscripts 0 and $\infty$ stand for the initial and final mass of decomposing material respectively while $\mathrm{w}$ denotes the mass at any time. $f(\alpha)$ is the kinetic function related to the reaction mechanism. Many different equations for $f(\alpha)$ each has certain reasonable theoretical grounds are given in literature for the solid phase decomposition reactions $[10,11]$. Some of them, 
which are tested by the experimentally obtained mass change data, are listed in Table 1.

Normally Arrhenius expression is used for the rate constant:

$\mathrm{k}=\operatorname{Aexp}\left(-\frac{\mathrm{E}}{\mathrm{RT}}\right)$

(3)

Here E, $\mathrm{A}$ and $\mathrm{R}$ are the activation energy, preexponential factor and gas constants respectively. Then, Eq. (2) becomes.

$\frac{\mathrm{d} \propto}{\mathrm{dt}}=\operatorname{Aexp}\left(-\frac{\mathrm{E}}{\mathrm{RT}}\right) \mathrm{f}(\propto)$

(4)

Reaction time and temperature can be used interchangeably when the sample temperature increases linearly with time during reaction. If linear heating rate is b, Eq. (4) can be written as.

$\frac{\mathrm{d} \alpha}{\mathrm{dT}}=\frac{\mathrm{A}}{\mathrm{b}} \exp \left(-\frac{\mathrm{E}}{\mathrm{RT}}\right) \mathrm{f}(\alpha)$

Integration gives $\mathrm{g}(\alpha)$

$\mathrm{g}(\alpha)=\int_{0}^{\alpha} \frac{\mathrm{d} \alpha}{\mathrm{f}(\alpha)}=\frac{\mathrm{A}}{\mathrm{b}} \int_{0}^{\mathrm{T}_{\alpha}} \exp \left(-\frac{\mathrm{E}}{\mathrm{RT}}\right) \mathrm{dT}$

The expressions of $g(\alpha)$ corresponding to each kinetic function are also shown in Table 1. It is possible to determine kinetic parameters by using either kinetic function or its integral. In the integral method, the integral on the right side of Eq. (6) should be solved. Unfortunately, it has no exact analytical solution and some approximations are generally used. If $\mathrm{u}=\mathrm{E} / \mathrm{RT}$ is defined, Eq. (6) can be written in the following form.

$\mathrm{g}(\propto)=\frac{\mathrm{AE}}{\mathrm{bR}} \int_{\mathrm{u}}^{\infty} \frac{\exp (-\mathrm{u})}{\mathrm{u}^{2}} \mathrm{du}=\frac{\mathrm{AE}}{\mathrm{bR}} \mathrm{p}(\mathrm{u})$

where $\mathrm{p}(\mathrm{u})$ represent the rightmost term known as the temperature integral in Eq. (6). In the Coats and Redfern method, p(u) in Eq. (7) is approximated by using a Taylor series expansion to yield the following expression (12):

$\ln \frac{\mathrm{g}(\alpha)}{\mathrm{T}^{2} \mathrm{Q}(\mathrm{E} / \mathrm{RT})}=\ln \frac{\mathrm{AR}}{\mathrm{bE}}-\frac{\mathrm{E}}{\mathrm{RT}}$

Table 1. Algebraic expressions for $f(\alpha)$ and $g(\alpha)$ considered in this work

\begin{tabular}{|c|c|c|}
\hline Kinetic Models & $\mathrm{f}(\alpha)$ & $\mathrm{g}(\alpha)$ \\
\hline $\begin{array}{c}\text { Parabolic Law } \\
\text { (D1) }\end{array}$ & $\frac{1}{\alpha}$ & $\frac{\alpha^{2}}{2}$ \\
\hline Holt-Cutler- \\
Wadsword (D2) & $1 /-\ln (1-\alpha)$ & $(1-\alpha) \ln (1-\alpha)+\alpha$ \\
\hline $\begin{array}{c}\text { Jander } \\
\text { (D3) }\end{array}$ & $\frac{(1-\alpha)^{2 / 3}}{1-(1-\alpha)^{1 / 3}}$ & $\frac{3}{2}(1$ \\
\hline $\begin{array}{c}\text { Ginstling-Brounshtein } \\
\text { (D4) }\end{array}$ & $\frac{(1-\alpha)^{1 / 3}}{1-(1-\alpha)^{1 / 3}}$ & $\frac{3}{2}\left(1-\frac{2 \alpha}{3}\right.$ \\
& & $\left.-(1-\alpha)^{1 / 3}\right)^{2}$ \\
\hline
\end{tabular}

\begin{tabular}{|c|c|c|}
\hline $\begin{array}{c}\text { Zhuravlev-Lesokhin- } \\
\text { Tempelmen (D5) }\end{array}$ & $\frac{(1-\alpha)^{5 / 2}}{1-(1-\alpha)^{1 / 3}}$ & $\frac{3}{2}\left((1-\alpha)^{-\frac{1}{3}}\right.$ \\
\hline $\begin{array}{c}\text { Komatsu-Uemuro } \\
\text { (anti Jander) (D6) }\end{array}$ & $\frac{(1+\alpha)^{2 / 3}}{(1+\alpha)^{1 / 3}-1}$ & $\frac{3}{2}\left((1+\alpha)^{\frac{1}{3}}-1\right)^{2}$ \\
\hline
\end{tabular}

Table 2. Proximate analyse results of the pine wood sample (\%w)

\begin{tabular}{|l|c|}
\hline Moisture & 5.12 \\
\hline Volatile matter & 80.73 \\
\hline Ash & 1.10 \\
\hline Fixed carbon* & 13.05 \\
\hline *: By difference
\end{tabular}

\section{Results and Discussion}

Proximate analysis results of pinewood are given in Table 2. The amount of volatile matter implies that more than $80 \%$ of pinewood could be volatilized under thermal decomposition conditions. Figs. 2, 3, 4 show mass recording results of pine sawdust during pyrolysis at three heating rates from room temperature to $500{ }^{\circ} \mathrm{C}$. It is clearly seen that thermal decomposition curves look like traditional TGA curves and can be divided into three regions according to their changing pattern. The first region of small slope may be attributed to evaporation of physically adsorbed water, smaller molecular weights volatiles and partial decomposition of hemicelluloses. The second region of higher slope than the first represents predominantly decomposition of major wood components of hemicelluloses, cellulose and lignin. In the third region of small slope secondary decomposition reactions of major wood components take place [5]. In order to get better fit of the data for the selected models, two temperature regions, over which certain wood components predominantly decompose, were assumed. Mass loss over 473 - $593 \mathrm{~K}$ range is contributed by decomposition of mainly hemicelluloses, lesser extent cellulose and weakly lignin, whereas mass loss over $593-773 \mathrm{~K}$ range is contributed moderately by decomposition of cellulose and mainly lignin. For this reason, regression tests are separately applied for conversion ratio data corresponding to these regions. The results obtained with these models are given in Table 3. It can be seen that quality of fit or regression coefficients are not high for $5 \mathrm{~K} / \mathrm{min}$. and increase with heating rate, reaching to 0.968 for Zhurovlev-Lesokhin-Tempelman model. However, none of the models seem to have any appearent superiority to others for the two temperature ranges and at three heating rates. Thus, only kinetic parameters are seen to be comparable with the results obtained for similar biomasses. Activation energies change between 18.0-20.1, 24.4-32.8 and 44.5-47.8 $\mathrm{kJ} / \mathrm{mole}$ for heating rates of 5,10 and $15 \mathrm{~K} / \mathrm{min}$. respectively, which imply effect of chemical control on the volatiles evolution during pyrolysis increase with 
heating rate. For a single heating rate, the differences between magnitudes of activation energies are not considerable. However, values of activation energies are higher at higher heating rates.

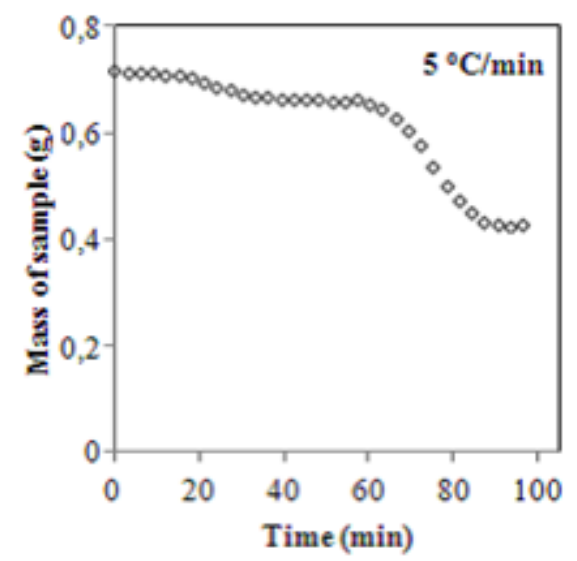

Figure 2. Changes in mass of pine wood during pyrolysis at $5{ }^{\circ} \mathrm{C} / \mathrm{min}$ heating rates to $500^{\circ} \mathrm{C}$

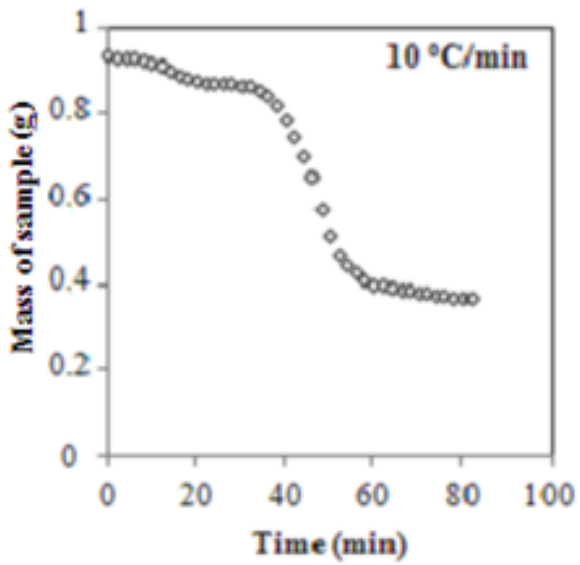

Figure 3. Changes in mass of pine wood during pyrolysis at $10^{\circ} \mathrm{C} /$ min heating rates to $500^{\circ} \mathrm{C}$

Table 3. Kinetic parameters from regression analysis of conversion ratios for final temperature of $773 \mathrm{~K}$

\begin{tabular}{|c|c|c|c|c|c|c|}
\hline $\begin{array}{c}\text { Heating rate } \\
(\mathrm{K} / \mathrm{min})\end{array}$ & Mathematical Model & Components & $\begin{array}{c}\text { Temperature } \\
\text { range }(\mathbf{K})\end{array}$ & $\begin{array}{c}\text { Ea } \\
(\mathbf{K J} / \mathbf{m o l}) \\
\end{array}$ & $\begin{array}{c}\mathbf{A} \\
\left(\mathbf{m i n}^{-1}\right)\end{array}$ & $\mathbf{R}^{2}$ \\
\hline \multirow{12}{*}{5} & \multirow{2}{*}{ Parabolic Law } & Hemicel.+ Cellulose & $473-593$ & 18.7 & 0.007 & 0.842 \\
\hline & & Lignin & $593-773$ & 19.0 & 0.002 & 0.818 \\
\hline & \multirow{2}{*}{ Holt - Cutler - Wadsworth } & Hemicel.+ Cellulose & $473-593$ & 19.1 & 0.008 & 0.844 \\
\hline & & Lignin & $593-773$ & 19.5 & 0.002 & 0.819 \\
\hline & \multirow{2}{*}{ Jander } & Hemicel.+ Cellulose & $473-593$ & 19.4 & 0.003 & 0.847 \\
\hline & & Lignin & $593-773$ & 20.0 & 0.001 & 0.821 \\
\hline & \multirow{2}{*}{ Ginstling - Brounshtein. } & Hemicel.+ Cellulose & $473-593$ & 19.2 & 0.003 & 0.845 \\
\hline & & Lignin & $593-773$ & 19.7 & 0.001 & 0.820 \\
\hline & \multirow{2}{*}{$\begin{array}{l}\text { Zhurovlev-Lesokhin } \\
\text { Tempelman }\end{array}$} & Hemicel.+ Cellulose & $473-593$ & 20.1 & 0.004 & 0.851 \\
\hline & & Lignin & $593-773$ & 21.1 & 0.001 & 0.824 \\
\hline & \multirow{2}{*}{ Komatsu - Uemura } & Hemicel.+ Cellulose & $473-593$ & 18.1 & 0.002 & 0.837 \\
\hline & & Lignin & $593-773$ & 18.0 & 0.001 & 0.814 \\
\hline \multirow{9}{*}{10} & \multirow{2}{*}{ Parabolic Law } & Hemicel.+ Cellulose & $473-593$ & 31.4 & 0.065 & 0.909 \\
\hline & & Lignin & $593-773$ & 25.6 & 0.005 & 0.892 \\
\hline & \multirow{2}{*}{ Holt - Cutler - Wadsworth } & Hemicel.+ Cellulose & $473-593$ & 31.7 & 0.072 & 0.910 \\
\hline & & Lignin & $593-773$ & 26.3 & 0.006 & 0.892 \\
\hline & \multirow{2}{*}{ Jander } & Hemicel.+ Cellulose & $473-593$ & 32.1 & 0.027 & 0.912 \\
\hline & & Lignin & $593-773$ & 26.9 & 0.002 & 0.893 \\
\hline & \multirow{2}{*}{ Ginstling - Brounshtein } & Hemicel.+ Cellulose & $473-593$ & 31.9 & 0.025 & 0.911 \\
\hline & & Lignin & $593-773$ & 26.5 & 0.003 & 0.893 \\
\hline & $\begin{array}{lll}\text { Zhurovlev } \quad- & \text { Lesokhin }\end{array}$ & Hemicel.+ Cellulose & $473-593$ & 32.8 & 0.034 & 0.914 \\
\hline
\end{tabular}

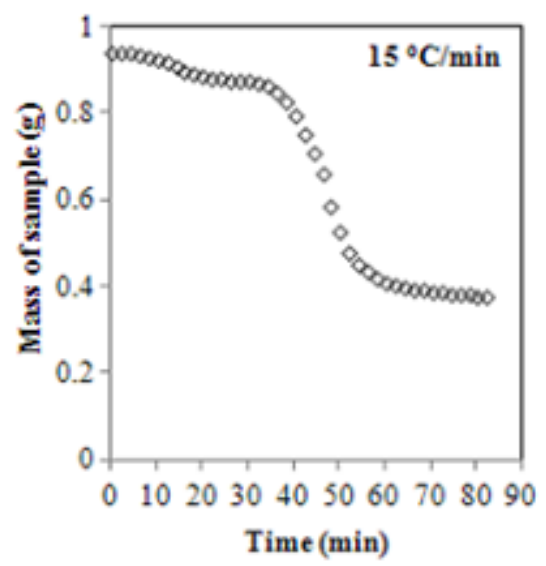

Figure 4. Changes in mass of pine wood during pyrolysis at $15{ }^{\circ} \mathrm{C} /$ min heating rates to $500^{\circ} \mathrm{C}$ 


\begin{tabular}{|c|c|c|c|c|c|c|}
\hline & Tempelman & Lignin & $593-773$ & 28.3 & 0.004 & 0.894 \\
\hline & Kometou U Umum & Hemicel.+ Cellulose & $473-593$ & 30.7 & 0.018 & 0.907 \\
\hline & nomatsu - vemura & Lignin & $593-773$ & 24.4 & 0.002 & 0.890 \\
\hline \multirow{12}{*}{15} & \multirow{2}{*}{ Parabolic Law } & Hemicel.+ Cellulose & $473-593$ & 46.7 & 3.365 & 0.965 \\
\hline & & Lignin & $593-773$ & 45.3 & 1.198 & 0.956 \\
\hline & \multirow{2}{*}{ Holt - Cutler - Wadsworth } & Hemicel.+ Cellulose & $473-593$ & 47.0 & 3.684 & 0.966 \\
\hline & & Lignin & $593-773$ & 44.5 & 1.247 & 0.954 \\
\hline & \multirow{2}{*}{ Jander } & Hemicel.+ Cellulose & $473-593$ & 47.2 & 1.346 & 0.966 \\
\hline & & Lignin & $593-773$ & 45.1 & 1.258 & 0.958 \\
\hline & \multirow{2}{*}{ Ginstling - Brounshtein. } & Hemicel.+ Cellulose & $473-593$ & 47.1 & 1.266 & 0.966 \\
\hline & & Lignin & $593-773$ & 44.8 & 1.207 & 0.956 \\
\hline & \multirow{2}{*}{$\begin{array}{lll}\text { Zhurovlev } & - & \text { Lesokhin } \\
\text { Tempelman } & & \\
\end{array}$} & Hemicel.+ Cellulose & $473-593$ & 47.8 & 1.618 & 0.968 \\
\hline & & Lignin & $593-773$ & 46.1 & 1.358 & 0.959 \\
\hline & \multirow{2}{*}{ Komatsu - Uemura } & Hemicel.+ Cellulose & $473-593$ & 46.1 & 0.945 & 0.964 \\
\hline & & Lignin & $593-773$ & 44.6 & 1.124 & 0.953 \\
\hline
\end{tabular}

\section{Conclusions}

Regression coefficients for the tested models are not high for $5 \mathrm{~K} / \mathrm{min}$. However, they tend to increase with heating rate.

None of the models seems to have any appearent superiority to others for the two temperature ranges and at three heating rates.

For a single heating rate, the differences between magnitudes of activation energies for the proposed models are not considerable.

The level of activation energies for volatiles evolution during pyrolysis imply contribution of diffusion control for lower heating rates and increasing effect of chemical control with increasing heating rate.

\section{References}

[1] L. J. R. Nunes, J.C.O. Matias, J. P. S. Catalão, "Mixed biomass pellets for thermal energy production: a review of combustion models," Apply Energy, vol.127, pp. 135-40, 2014.

[2] S. W. Du, W. H. Chen, J. A. Lucas, "Pre-treatment of biomass by torrefaction and carbonization for coal blend used in pulverized coal injection," Bio-resource Technology, vol. 09, pp. 161-333, 2014.

[3] L. Li, N. Zhao, X. Fu, M. Shao, S. Qin, "Thermogravimetric and kinetic analysis of spirulina wastes under nitrogen and air atmospheres," Bio-resource Technology, vol. 140, pp. 152-157, 2003.

[4] P. McKendry, "Energy production from biomass conversion technologies," Bio-resource Technology, vol. 83, pp. 47-54, 2002.

[5] J. M. Prins, J. K. Ptasinski, F. J. J. G. Janssen, J. Krzysztof, "Torrefaction of wood weight loss kinetics," JAnalApplPyrolysis, vol. 34, pp. 77-28, 2006.

[6] C. Di Blasi, "Modeling chemical and physical processes of wood and biomass pyrolysis," Prog. Energy Combustion, vol. 34, pp.47-90, 2008.

[7] T. H. Damartzis, D. Vamvuka, S. Sfakiotakis, A. Zabaniotou, "Thermal degradation studies and kinetic modeling of cardoon pyrolysis using thermogravimetric analysis," Bio-resource Technology, vol. 102, pp. 6230-6238, 2011.

[8] S. Y. Yorulmaz, A. T. Atimtay, "Investigation of combustion kinetics of treated and untreated waste wood samples with thermo-gravimetric analysis," Fuel Process Technology, vol. 90, pp. 939-946, 2009.

[9] E. S. Ella, G. Yuan, T. A. Mays, Simple kinetic analysis to determine the intrinsic reactivity of coal chars, Fuel Process Technology, vol. 84, pp.19201925, 2005.

[10] J. J. M. O'rfao, F. G. Martins, "Kinetic analysis of thermo-gravimetric data obtained under linear temperature programming-a method based on calculations of the temperature integral by interpolation," Thermochimica Acta, vol. 390, pp. 195211, 2002.

[11] J. E. White, W. J. Catallo, B. L. Legendre, "Biomass pyrolysis kinetics: A comparative critical review with relevant agricultural residue case studies," JAnalApplPyrolysis, vol. 91, pp. 1-33, 2011 